\title{
REFORMAS EN AMPARO Y DERECHOS COLECTIVOS ${ }^{1}$
}

\author{
Maricela Valenzuela Sánchez
}

\section{Resumen}

La modernidad y el desarrollo han conducido a los seres humanos a niveles superiores de vida, pero al mismo tiempo han provocado abusos en el entorno y de igual manera suscitado situaciones adversas para el ejercicio pleno de los derechos. Para enfrentarse a las nuevas realidades surgieron los derechos de tercera generación "Derechos Colectivos", así como se han perfilado mecanismos procesales para proteger los intereses colectivos, difusos o incluso individuales, pero éstos pueden incidir colectivamente.

Ahora bien, la problemática del fenómeno de lo "colectivo" comienza desde la terminología misma que se utiliza para su identificación, al no existir homogeneidad o univocidad en el lenguaje. Se utilizan indistintamente los sustantivos "derechos" o "intereses" para los adjetivos: colectivos, difusos, sociales, de grupo, clase, serie, sector, categoría, incidencia colectiva, transpersonales, supraindividuales, superindividuales, metaindividuales, transindividuales, etcétera. El problema de vocabulario se agudiza aún más si se agregan aquellos derechos auténticamente individuales que por conveniencia se ejercen de manera colectiva; es decir, los llamados derechos: accidentalmente colectivos, individuales homogéneos, entre otros, que tienen como característica ser divisibles y provenir de una causa común.

\footnotetext{
${ }^{1}$ Ensayo realizado para la asignatura Adecuación del Estado y la Administración Pública en México, Programa de Doctorado en Administración Pública, ISAPAC
} 


\section{Introducción}

En el entendido de que a nuevas realidades deben corresponder nuevos derechos y nuevos medios de protección procesal, de ahí que en la actualidad se hayan establecido los Derechos Colectivos, llamados también Derechos de Tercera Generación, los cuales se inspiran como lo enunciara Karel Vasak, en una "cierta concepción de la vida humana en comunidad"; tales derechos "sólo pueden ponerse en práctica gracias al esfuerzo conjunto de todos: desde los individuos y los estados hasta las entidades y órganos públicos y privados". Dichos derechos son, entre otros: a la paz, al desarrollo, a la libre determinación de los pueblos, a un medio ambiente sano y ecológicamente equilibrado y a beneficiarse del patrimonio común de la humanidad, bienes que tradicionalmente no estaban en el comercio, como el aire, el agua u otros elementos del medio ambiente, pero que pueden fácilmente contaminarse por la industria, la explosión demográfica u otras causas, para esto se deben de plantear las bases constitucionales y legales que permitan establecer las acciones y procesos colectivos, en las cuales tendrán que establecerse reglas especiales y diferentes para la legitimación, el proceso e incluso la cosa juzgada.

\section{Desarrollo del Tema}

En los últimos años se han llevado a cabo reformas centradas en un medio ordinario de defensa para proteger los intereses colectivos las cuales son transcendentales para el sistema jurídico mexicano, ya que se crean mecanismos para instrumentar el procedimiento de las acciones de clase o de grupo que hayan sido afectados en la protección de los derechos del consumidor, en el sistema de ecología, los servicios financieros o alguna otra acción en los que no se les han reconocido sus derechos de grupos. 
A continuación se enuncian las principales reformas en materia de Derechos Colectivos:

1.- El día 29 de julio de 2010 se adicionó el párrafo tercero del artículo 17 constitucional para establecer que el Congreso de la Unión expedirá las leyes que regulen las acciones colectivas.

2.- El 30 de agosto de 2011 se publicó el Decreto por el que se reforman y adicionan el Código Federal de Procedimientos Civiles, el Código Civil Federal, la Ley Federal de Competencia Económica, la Ley Federal de Protección al Consumidor, la Ley Orgánica del Poder Judicial de la Federación, la Ley General del Equilibrio Ecológico y la Protección al Ambiente y la Ley de Protección y Defensa al Usuario de Servicios Financieros. Por su parte, las reformas constitucionales del 6 y 10 de junio de 2011 se traducen en un nuevo paradigma al que se deben enfrentar los jueces del país, en virtud que se rediseña el sistema jurisdiccional mexicano; toda vez que con la primera reforma se actualiza al juicio de amparo y con la segunda se amplía la protección de los derechos humanos, estableciéndose principios importantes como el de "pro persona" o pro homine, así como el de control de convencionalidad ex officio; por lo que, para nuestro tema, interesa que se establecen las bases mínimas para acceder al juicio de amparo de manera colectiva.

\section{Juicio de Amparo Colectivo}

De conformidad con lo dispuesto por los artículos 103 y 107 de la Constitución Política de los Estados Unidos Mexicanos, el juicio de amparo es un medio para combatir normas generales, actos $u$ omisiones de la autoridad que vulneren los derechos humanos reconocidos y las garantías otorgadas para su protección por dicha constitución, así como por los tratados internacionales de los que el Estado mexicano sea parte; como se estableció con anterioridad, las 
reformas constitucionales del 6 y 10 de junio de 2011 resultan trascendentes como pilares del actual juicio de amparo, lo cual fue robustecido con la publicación el 2 de abril de 2013, de la actual Ley de Amparo.

Eduardo Ferrer Mac-Gregor afirma, desde una noción contemporánea, que la expresión "amparo" se utiliza para significar al "juicio constitucional de amparo", es decir, una garantía judicial, un proceso constitucional, un mecanismo de protección específico para salvaguardar los derechos fundamentales dentro de los sistemas de control de la constitucionalidad de leyes y dentro de la concepción genérica de la defensa de la Constitución.

El Doctor Alfonso Herrera García señala que la necesidad de un renovado objeto de protección, en un sentido expansivo hacia el orden internacional de los derechos humanos, mantuvo un consenso indiscutido tanto a lo largo del proceso de reforma a los artículos 103 y 107 constitucionales como en el proceso legislativo que dio lugar a la nueva Ley de Amparo, hoy en vigor.

Para Lucio Cabrera Acevedo, el juicio de amparo ha sido y puede llegar a ser una medida procesal correcta para la prevención de los daños, pues anula el acto reclamado y cuando se concede ordena que vuelvan las cosas al estado anterior de la violación, para dicho autor el amparo colectivo puede ser el mejor medio procesal preventivo de daños.

\section{Ejemplos relevantes de amparos colectivos en México.}

1. La Suprema Corte de Justicia de la Nación, analizó un asunto colectivo, al resolver el amparo directo civil 15/2009 en relación con el amparo directo civil 14/2009, el cual derivó de un juicio ordinario civil promovido en ejercicio de la acción de grupo prevista por el artículo 26, fracción I, de la Ley Federal de Protección al Consumidor, en el que se reclamó que una empresa realizó 
conductas que ocasionaron daños y perjuicios a un grupo de consumidores, ya que la referida persona moral construyó viviendas de interés social y realizó operaciones de venta de inmuebles destinados a casa habitación.

2. Otro ejemplo de amparo colectivo trascendente en nuestro sistema es la resolución emitida el 10 de agosto de 2016 por la Primera Sala de la Suprema Corte de Justicia de la Nación en el amparo en revisión 54/2016, en el sentido de determinar que la separación del servicio profesional docente por no acreditar las condiciones de permanencia en el cargo, no constituye una sanción administrativa.

\section{Conclusiones}

De lo anterior se puede concluir que la práctica cotidiana indicará los alcances que se le debe dar al amparo colectivo para dar seguridad jurídica a los gobernados y lograr que cumplan con su finalidad, es decir, que exista una mayor apertura y acceso a la justicia. Cabe precisar que aún son incipientes los asuntos que se tramitan por esa vía, por lo que es necesario que se planteen mayores demandas de esa naturaleza, para fortalecer esa institución jurídica, y los juzgadores con la práctica vayan perfeccionando los criterios.

Actualmente, no existe una regulación específica sobre el amparo colectivo en la Ley de Amparo, por lo que éste se rige de acuerdo a las disposiciones generales contenidas en esa Ley y en el Código Federal de Procedimientos Civiles; el amparo colectivo sirve para reclamar actos $u$ omisiones que afecten nuestros derechos fundamentales. Por ejemplo, cuando la Secretaría de Medio Ambiente y Recursos Naturales autoriza ambientalmente un proyecto que puede resultar dañino para una comunidad y para un ecosistema se puede promover un amparo indirecto, para intentar revertir esa autorización por ir en contra del derecho a contar con un medio ambiente sano, de acuerdo al artículo 4o. de la Constitución. 
Ante las limitantes contenidas en la Ley de Amparo y en el Código Federal de Procedimientos Civiles, el juzgador debe interpretar las normas y los hechos de forma compatible con los principios y objetivos de los procedimientos colectivos, en aras de proteger y tutelar el interés general y los derechos e intereses colectivos, es decir, los juzgadores deben propiciar que estos procedimientos sean cada vez más ágiles, sencillos y flexibles en aras de que las pretensiones de la colectividad gocen de un efectivo acceso a la justicia.

\section{Bibliografía}

Fix-Zamudio, Héctor y Valencia Carmona, Salvador, Las reformas en derechos humanos, procesos colectivos y amparo como nuevo paradigma constitucional, México, Porrúa, 2013, pp. 56 y 57.

Diccionario de derecho procesal constitucional y convencional, México, Poder Judicial Federal Consejo de la Judicatura Federal UNAM, Instituto de Investigaciones Jurídicas, 2014, t. I, p. 58.

Herrera García, Alfonso, El objeto de protección del nuevo juicio de amparo, México, UNAM, Instituto de Investigaciones Jurídicas, p. 347.

Cabrera Acevedo, Lucio, El amparo colectivo protector del derecho al ambiente y de otros derechos humanos, 2a. ed., México,Porrúa, 2006, pp.5y6. 